\title{
HIBRIDAÇÃO INTERESPECÍFICA ENTRE GOSSYPIUM HIRSUTUM L. VAR. LATIFOLIUM E G. HERBACEUM L. VAR. AFRICANUM $\left.{ }^{1}{ }^{1}\right)$
}

\author{
EDERALDO JOSE CHIAVEGATO $\left({ }^{2},{ }^{5}\right)$, IMRE LAJOS GRIDI-PAPP $(2,5)$, \\ JULIO ISAO KONDO $\left({ }^{3,5}\right)$ e DIXIER MAROZZI MEDINA $\left(^{4}\right)$
}

\begin{abstract}
RESUMO
Foi obtida, pelos autores, variabilidade genética para resistência da fibra do algodoeiro a partir da hibridação entre a espécie alotetraplóide cultivada Gossypium hirsutum $I$. var. latifolium Hutch. e a espécie diplóide selvagem $G$. herbaceum L. var. africanum Hutch. A metodologia empregada e as características agronômicas e tecnológicas da fibra do híbrido são descritas e discutidas. Visando à duplicação do númeto de cromossomos da espécie diplóide, foram realizados nove tratamentos com o alcalóide colchicina, em solução aquosa e em adição com pasta de lanolina, com diferentes concentraçōes e tempo de ação para o tratamento de sementes, radicelas e gemas apicais: revelou-se mais eficiente o de gemas apicais com colchicina a $1 \%$, em pasta de lanolina, durante 32 horas. Diversos cruzamentos das plantas duplicadas com variedades comerciais de algodoeiro levaram à obtenção de hf́brido estéril. A seguir, dois retrocruzamentos foram realizados, sendo que, a partir do primeiro, a fertilidade foi restaurada. Estas plantas, com características agronômicas promissoras, possuem grande variabilidade para resistência da fibra, num nivel superior ao de $G$. hirsutum.
\end{abstract}

Termos de indexação: melhoramento algodoeiro; G. hirsutum x G. herbaceum; duplicação cromossômica.

$\left({ }^{1}\right)$ Recebido para publicação em 15 de junho de 1984.

$\left.{ }_{3}^{2}\right)$ Seçāo đe Algodāo, Instituto Agronômico (IAC), Caixa Postal 28, 13100 Campinas (SP).

$\left.{ }_{4}^{3}\right)$ Seção de Tecnologia de Fibras, IAC.

$\left({ }_{5}^{4}\right)$ Seçāo de Citologia, IAC.

(5) Com bolsa de suplementaçąo do CNPq. 


\section{INTRODUÇĀO}

Gossypium hirsutum L. é a espécie alotetraplóide de algodoeiro mais importante na produção de fibra têxtil natural. Caracterizada pelo genômio (AD) ${ }_{1}$ (BEASLEY, 1940), constituído de um comportamento cromossômico asiático e outro proveniente de uma espécie diplóide americana, tem sido objeto dos mais variados métodos de melhoramento genético. A identificação de características de interesse nessas duas espécies que a constituem, serve de base para a elaboração de programas de melhoramento que visam as suas melhores combinaçðes (MEYER, 1953).

As espécies selvagens e, possivelmente, as asiáticas cultivadas $G$. arboreum e $G$. herbaceum, segundo LODEN (1951), podem ser consideradas as mais importantes fontes de variabilidade genética e caracteres desejáveis.

Vários autores, observando outras espécies do gênero Gossypium, não raro diplóides, indicam a presença de caracteres de valor econômico, e o sucesso da sua transferência pode ser de grande interesse no melhoramento do $G$. hirsutum. Ê evidente, porém, que os trabalhos de hibridação interespecífica, em geral, são complexos, não somente pela falta de homologia dos cromossomos como pela diferença no número de cromossomos das espécies envolvidas.

Os programas de hibridação com espécies diplóides e tetraplóides requerem a utilização de agentes duplicadores do número de cromossomos, sendo o alcalóide colchicina o mais utilizado em algodoeiro (AMIN, 1941; MENDES, 1939, 1942; MIRZA, 1974; STEPHENS, 1940, 1954).

Híbridos entre espécies tetraplóides cultivadas e espécies diplóides selvagens têm sido estudados por diversos autores, em dois tipos de pesquisas, visando, de um lado, determinar as características de valor econômico existentes nas espécies relacionadas ao algodoeiro cultivado, e, de outro, examinar os métodos de melhoramento mais adequados que permitam incorporá-las às variedades comerciais (STEPHENS, 1954).

O presente trabalho teve por objetivo a obtenção de variabilidade genética quanto à resistência da fibra, a partir da hibridação entre a espécie alotetraplóide cultivada Gossypium hirsutum L. var. latifolium Hutch. e a espécie diplóide selvagem $G$. herbaceum $\mathrm{L}$ var. africanum Hutch, no sentido de aproveitá-la no melhoramento das variedades paulistas de algodoeiro e de colocar o material obtido à disposição dos melhoristas em diferentes programas de melhoramento. 


\section{MATERIAL E MÉTODOS}

\subsection{Material}

Para a obtenção de variabilidade genética quanto à resistência da fibra e à transferência desta para as atuais variedades comerciais alotetraplóides IAC 17, IAC 18 e IAC 19 de G. hirsutum var. latifolium, do genômio $(\mathrm{AD})_{1}$, número haploide igual a 26 cromossomos, sendo 13 grandes e 13 pequenos, foi escolhida a espécie diplóide Gossypium herbaceum L. var. africanum Hutch., perene, existente em estado selvagem na África do Sul, apresentando número haplóide igual a 13 cromossomos grandes, caracterizada pelo genômio $A_{1}$, registrada na coleção da Seção de Algodão do Instituto Agronomico, sob o indice Af-2, de fibra grossa, curta e resistente.

\subsection{Tratamentos}

Para efetuar essa hibridação interespecífica, uma vez envolvidas espécies com diferentes números de cromossomos, fez-se necessário utilizar um agente duplicador de cromossomos. Empregou-se o alcalóide colchicina, em solução aquosa e em mistura com lanolina, para o tratamento de sementes, radicelas e gemas apicais da espécie diplóide.

Programou-se, primeiro, a duplicação dos cromossomos do diplóide africanum, para posteriormente cruzá-lo com G. hirsutum.

Como africanum é a forma selvagem de $G$. herbaceum, presumiu-se a existência de grande número de sementes dormentes. Portanto, para uniformizar a germinação e facilitar a absorção da colchicina pelas sementes, estas foram escarificadas previamente com ácido sulfúrico concentrado, por três horas, lavadas em água corrente e secas em estufa.

Em todos os tratamentos, foram utilizadas placas de Petri ou caixas plásticas forradas com esponja sintética de $5 \mathrm{~mm}$, para a germinação das sementes tanto em água como em solução aquosa de colchicina.

O processo de germinação, assim como os tratamentos de sementes e de radicelas, ocorreram o tempo todo em câmara com temperatura controlada para $28^{\circ} \mathrm{C}$. Com exceção do tratamento 4 , no qual as sementes permaneceram todo o tempo em solução aquosa de colchicina, todos os demais tratamentos de sementes e radicelas foram realizados na segunda noite após o início do processo germinativo, tendo em vista que a maior absorção de água pela semente se dá neste periodo (GRIDI-PAPP, 1966).

Após a emissão das radicelas pelas sementes, estas foram plantadas definitivamente em vasos em casa de vegetação. 
Os tratamentos abaixo relacionados, realizados com G. hirsutum var. africanum visando à tetraploidia, foram baseados em trabalhos de MENDES (1939), STEPHENS (1940) e BEASLEY (1940), com particularidades que se fizeram necessárias no presente trabalho, procurando-se adequar a parte da planta tratada, a concentração da solução e o tempo de ação.

Tratamento 1: Tratamento de sementes por absorção em solução aquosa de colchicina $0,15 \%$ por 16 horas - Foram colocadas 30 sementes em placas de Petri contendo individualmente $6 \mathrm{ml}$ de água e, após 26 horas, transferidas para outras placas contendo $6 \mathrm{ml}$ de solução aquosa de colchicina $0,15 \%$, onde permaneceram por 16 horas, retornando posteriormente a placas com água para continuarem o processo germinativo.

Tratamento 2: Tratamento de sementes por absorção em solução aquosa de colchicina $0,15 \%$ por 21 horas - Foram colocadas 36 sementes em placas de Petri contendo individualmente $6 \mathrm{ml}$ de água, e, após 26 horas, transferidas para outras placas contendo $6 \mathrm{ml}$ de solução aquosa de colchicina $0,15 \%$, onde permaneceram por 21 horas; posteriormente, foram colocadas novamente em placas com água para continuarem o processo germinativo.

Tratamento 3: Tratamento de sementes por absorção em solução aquosa de colchicina $0,15 \%$ por 28 horas - Foram colocadas 40 sementes em placas de Petri contendo individualmente $6 \mathrm{ml}$ de água, e, passadas 26 horas, transferidas para outras placas contendo $6 \mathrm{ml}$ de solução aquosa de colchicina $0,15 \%$, onde permaneceram por 28 horas, sendo posteriormente recolocadas em placas com água para continuarem o processo germinativo.

Tratamento 4: Tratamento de sementes por absorção em solução aquosa de colchicina $0,075 \%$, durante todo o processo germinativo - Foram colocadas 36 sementes em placas de Petri contendo individualmente $6 \mathrm{ml} \mathrm{de}$ solução aquosa de colchicina $0,075 \%$, onde permaneceram durante todo o processo germinativo.

Tratamento 5: Tratamento de sementes por imersão em solução aquosa de colchicina $0,15 \%$ por 16 horas - Foram colocadas 680 sementes para germinar em caixas plásticas contendo individualmente $6 \mathrm{ml}$ de água para cada 30 sementes, e, decorridas 26 horas, foram transferidas para uma soluçăo aquosa de colchicina $0,15 \%$, onde permaneceram mergulhadas durante 16 horas, sendo posteriormente colocadas novamente com água para continuarem o processo germinativo.

Tratamento 6: Tratamento de radicelas por absorção em solução aquosa de colchicina $0,15 \%$ por 16 horas - Foram colocadas 30 sementes para germinar em placas de Petri contendo individualmente $6 \mathrm{ml}$ de água, até o início da emissão das radicelas. No momento em que a maioria das sementes se encontrava nestas condições, foram transferidas para outras placas con- 
tendo $6 \mathrm{ml}$ de solução aquosa de colchicina, onde, após 16 horas, foram retiradas e plantadas em vasos em casa de vegetação.

Tratamento 7:Tratamento de gemas apicais por imersão em solução aquosa de colchicina $0,15 \%$ durante 20 horas - Foram tratadas as gemas apicais de 10 plantas apresentando os primeiros pares de folhas definitivas, por imersão direta em solução aquosa de colchicina $0,15 \%$ durante 20 horas. Retiradas da solução, as gemas foram lavadas em água e, o material, mantido na casa de vegetação.

Tratamento 8: Tratamento de gemas apicais com pasta de lanolina + colchicina $0,5 \%$ - Foram colocadas 70 sementes para germinar em placas de Petri, contendo individualmente $6 \mathrm{ml}$ de água, e após a emissão das radicelas, as mais desenvolvidas e uniformes foram transferidas para vasos em casa de vegetação. Decorridos 10 dias do início do processo germinativo, foram tratadas as gemas apicais de 27 plantas ainda em estádio cotiledonar com pasta de lanolina + colchicina $0,5 \%$ durante 32 horas. Retirada a pasta, a parte tratada foi lavada em água e, o material, mantido na casa de vegetação.

Tratamento 9: Tratamento de gemas apicais com pasta de lanolina + colchicina $1,0 \%$ - 34 plantas receberam o tratamento com pasta de lanolina + colchicina $1,0 \%$, nos moldes do tratamento 8 .

\subsection{Metodologia de avaliação do efeito dos tratamentos}

Os tratamentos foram previamente avaliados com base no aumento do tamanho das células dérmicas da página inferior da folha, quando comparadas com plantas não tratadas. Estas observações foram feitas na folha do 40 nó do ponteiro para a base das plantas (GRIDI-PAPP, 1970). Posteriormente, nas plantas selecionadas, foi contado o número de cromossomos em células-mãe do grão de pólen, pelo método do carmim acético. Estas contagens foram feitas em botoes florais com $5,5 \mathrm{~mm}$ de comprimento, colhidos por volta das 9 h30min da manhã em dias normais, podendo ser retardadas em dias nublados (STEPHENS, 1940).

\subsection{Obtenção dos híbridos interespecificos}

Obtidas as plantas tetraplóides de G. herbaceum var. africanum, foram feitos, em casa de vegetação, 245 cruzamentos destas com as variedades comerciais de $G$. hirsutum IAC 17, IAC 18, IAC 19 e com a Hartswille da coleção de variedades da Seção de Algodão do Instituto Agronômico. A geração $F_{1}$ foi semeada na própria casa de vegetação.

Paralelamente, foram plantadas em condições de campo sementes obtidas das plantas duplicadas, visando adaptação prévia às condições ambien- 
tes, visto que aquela espécie é perene e originária da Africa, enquanto a agricultura paulista exige plantas anuais de ciclo curto.

Foi realizado, após o estudo do comportamento da geração $F_{1}$, o primeiro retrocruzamento para as variedades comerciais. Nos primeiros dias, os cruzamentos foram executados da maneira convencional, ou seja, colocando grande quantidade de pólen do pai duplicado no estigma das variedades comerciais. Logo a seguir, foram realizados, em duas etapas, 698 e 471 cruzamentos com a colocação de um a três grãos de pólen próprio, no estigma do pai receptor, juntamente com grande capacidade de pólen do pai duplicado, conforme utilizado por BEASLEY (1940), procurando auxiliar estes cruzamentos. As sementes oriundas foram plantadas em vasos em casa de vegetação, obtendo-se a geração $\mathrm{RC}_{1}$.

Das sementes autofecundadas obtidas destas plantas RC1, parte foi semeada em casa de vegetação, constituindo, portanto, a geração (RC1)2 para estudos e manutenção de tais plantas, e, parte, semeada em condições de campo, em 1982, em linhas de $10 \mathrm{~m}$, espaçadas de $1 \mathrm{~m}$, dentro de um programa de progênies e populações híbridas para estudos e continuidade do programa de melhoramento para obtenção de variedades.

Todas as plantas obtidas em condiçðes de campo foram selecionadas individualmente em vista da segregação da população, para estudos das características, em particular, tecnologicas de fibra.

Em 1983 foram realizados, em casa de vegetação, 153 cruzamentos visando obter o segundo e último retrocruzamento (RC2), sem a adição de pólen do pai receptor.

\section{RESULTADOS E DISCUSSÃO}

\subsection{Resultados dos tratamentos com colchicina}

Tratamento 1: De 30 sementes que receberam tratamento, apenas 4 não germinaram. As 26 plantas obtidas não mostraram um comportamento muito diferenciado entre si nem com relação às plantas não tratadas. Após observações feitas nas células dérmicas, a grande maioria, ou seja. 21 plantas foram eliminadas por não apresentarem alterações no seu tamanho e, as 5 restantes, mantidas para confirmações posteriores. Embora apresentassem algumas diferenças com relação às plantas não tratadas, como porte reduzido e folhas coriáceas, não foi verificada a tetraploidia, após contagem do número de cromossomos. 
Tratamento 2: De 36 sementes que receberam tratamento, 7 não germinaram. As 29 plantas restantes não mostraram diferença de comportamento entre si, nem com relação às plantas não tratadas, o que foi confirmado após observações do tamanho das células dérmicas, sendo, portanto, eliminadas, anulando-se assim este tratamento.

Tratamento 3: Do total de 40 sementes que receberam tratamento, 6 não germinaram. A grande maioria delas foi perdida após a emergência quando apresentaram reduzido desenvolvimento causado por intoxicação do alcalóide. Destas, apenas 11 plantas foram obtidas. Posteriormente, 7 foram eliminadas pelo critério do tamanho das células dérmicas e mantidas apenas 4, que apresentavam, além de maior tamanho das células, folhas coriáceas, desenvolvimento lento e baixa fertilidade. Após a contagem do seu número de cromossomos, duas mostraram-se duplicadas e outras duas, apesar de alguma altèração morfológica, não apresentaram tetraploidia.

Tratamento 4: Do total de 36 sementes que receberam tratamento, 10 não germinaram. As 26 plantas obtidas mostraram variações no comportamento, principalmente quanto ao porte. Posteriormente, 11 delas foram eliminadas por não apresentar alterações quanto ao tamanho das células dérmicas, sendo mantidas apenas 4. Após a contagem do número de seus cromossomos, 3 se mostraram duplicadas, não sendo verificada tetraploidia na quarta.

Tratamento 5: De um total de 680 sementes tratadas, grande número morreu por intoxicação, 140 sementes não germinaram e apenas 124 plantas foram obtidas. Destas, 104 foram eliminadas por não apresentar alterações no tamanho das células dérmicas e, 20, mantidas para posterior contagem do número de cromossomos em células-mãe do grão de pólen. Destas 20, 15 tiveram o seu número de cromossomos dobrados e 5 mostraram apenas alterações no seu número, ora para mais, ora para menos.

Tratamento 6: Do total de 30 sementes, apenas 5 não germinaram. Das 25 restantes que emitiram radicelas e receberam o tratamento, 15 foram plantadas em vaso e apenas uma sobreviveu, não demonstrando, após contagem do número de cromossomos, tetraploidia, embora apresentasse alteraçōes morfológicas, como folhas mais grossas e deformações nas brácteas.

Tratamento 7: Das 10 plantas, 8 morreram logo após o tempo de tratamento e apenas duas se mostravam promissoras, tendo, posteriormente, morte da parte tratada e apresentado brotações de gemas vegetativas logo abaixo da regiăo de tratamento. Nestas, apesar do desenvolvimento mais lento com relação às plantas não tratadas, não foi verificada a tetraploidia.

Tratamento 8: As 27 plantas tratadas não mostraram danos na região de tratamento e foram mantidas para confirmações posteriores. Após verificações das células dérmicas, 4 destas mostraram alterações quando com- 
paradas com plantas não tratadas, sendo mantidas. Feita a contagem do número de cromossomos, verificou-se apenas uma planta duplicada e $3 \mathrm{com}$ possíveis alterações na divisão cromossômica, em vista da baixa fertilidade apresentada.

Tratamento 9: Todas as 34 plantas tratadas também não mostraram danos na região de tratamento, sendo mantidas para confirmações posteriores. Oito foram mantidas depois de observações das células dérmicas Após a contagem do número de cromossomos, verificou-se a existência de 5 plantas duplicadas e duas que, embora apresentassem desenvolvimento semelhante às plantas duplicadas, não eram tetraplóides.

O resumo destes tratamentos pode ser observado no quadro 1 , onde são apresentados os números e as porcentagens das plantas duplicadas obtidas em cada um deles.

QUADRO l - Efeito dos tratamentos para obtençăo de plantas tetraploides de $G$. herbaceum var. africanum

\begin{tabular}{|c|c|c|c|c|c|c|c|c|c|}
\hline \multicolumn{3}{|c|}{ Tratamentos } & \multicolumn{2}{|c|}{ Plantas Duplicadas } & \multicolumn{2}{|c|}{ Plantas Normais } & \multicolumn{3}{|c|}{$\begin{array}{c}\text { Plantas con Alteraçסes } \\
\text { Inviáveis }\end{array}$} \\
\hline nọ & $\begin{array}{l}\text { Total de } \\
\text { sementes }\end{array}$ & $\begin{array}{c}\text { Total de } \\
\text { gemas apicais }\end{array}$ & no & $\%$ & nọ & $\%$ & no & & $\%$ \\
\hline 1 & 30 & - & 0 & 0,00 & 28 & 93,33 & 2 & $:$ & 6.66 \\
\hline 2 & 36 & - & 0 & 0.00 & 29 & 80.56 & 0 & & 0,00 \\
\hline 3 & 40 & - & 2 & 5,00 & 7 & 37.50 & 2 & & 5,00 \\
\hline 4 & 36 & - & 3 & 8,33 & 11 & 30,56 & 1 & & 2,78 \\
\hline 5 & 680 & - & 15 & 2,21 & 104 & 15,29 & 5 & & 0.74 \\
\hline 6 & 30 & - & 0 & 0,00 & 0 & 0,00 & 1 & & 3.33 \\
\hline 7 & - & 10 & 0 & 0,00 & 8 & 80,00 & 2 & & 20,00 \\
\hline 8 & - & 27 & 1 & 3,70 & 23 & 85,19 & 3 & & 11,11 \\
\hline 9 & - & 34 & 5 & 14,71 & 26 & 76,47 & 2 & & 5,88 \\
\hline
\end{tabular}

Em termos de duplicação cromossômica, destacou-se o tratamento 9 , que compreende o tratamento da gema apical com pasta de lanolina mais colchícina a $1 \%$, o que está de acordo com os resultados encontrados por STEPHENS (1940) em G. arboreum.

MENDES (1939), trabalhando com G. hirsutum e G. herbaceum cultivados, alcançou maior eficiência na obtenção de algodoeiros poliplóides mediante tratamento de sementes. Já no presente trabalho, estes tratamentos não foram satisfatórios, talvez pelo fato de as espécies selvagens normalmente apresentarem maior dormência das sementes, além de desuniformidade de germinação, como é o caso do G. herbaceum var. africanum. 
Dos tratamentos de sementes realizados, obteve-se melhor eficiència com o tratamento 4 , ou seja, por um maior tempo de açăo com menor concentração do alcalóide, resultando, portanto, em maior porcentagem de plantas duplicadas, $8,33 \%$, e apenas $2,87 \%$ de plantas com alterações inviáveis. O contrário ocorreu com os tratamentos 1,2 e 3 , onde foi auméntado gradativamente o tempo de ação do alcalóide, mantendo constante a concentração da solução. Embora tenham sido obtidas plantas tetraplóides quando do maior tempo de ação do alcalóide, ou seja, no tratamento 3, as perdas por intoxicação e alterações inviáveis tam bém foram maiores.

Os tratamentos 5,6 e 7 podem ser considerados como os mais drásticos de todos, tendo provocado a morte por intoxicação pelo alcalóide na maioria das plantas e sementes tratadas. Foram considerados, juntamente com os tratamentos 1 e 2 , como os menos eficientes nas condições em que foram realizados, para a espécie em questão.

\subsection{Estudo das plantas tetraplóides e populações híbridas obtidas}

As plantas tetraplóides obtidas apresentaram, em geral, semelhança fenotípica com as diplóides originais, com uma pequena alteração no aspecto coriáceo de suas folhas e um pequeno aumento no tamanho de suas flores que, embora em menor porcentagem, continuaram férteis Esse fato foi igualmente observado por outros autores, que trabalharam no assunto e também não encontraram tendência para "gigantismo" em algodoeiros poliplóides, como comumente ocorre com outras plantas (BEASLEY, 1940; MENDES, 1942).

As sementes obtidas das plantas duplicadas, plantadas em condições de campo para uma seleção prévia de materiais mais adaptados às nossas condições, deram poucas plantinhas que não conseguiram desenvolver-se além da fomação das primeiras folhas definitivas.

Do total de 245 cruzamentos envolvendo as plantas tetraplóides de $G$. herbaceum var. africanum com as variedades comerciais de $G$. hirsutum IAC 17, IAC 18, IAC 19 e a variedade Hartswille existente na coleção de variedades comerciais do Instituto Agronomico, foram obtidos quatro frutos, sendo dois da IAC $17 \mathrm{com} 11$ sementes, um da IAC $18 \mathrm{com}$ apenas uma semente e um com duas sementes da Hartswille.

As sementes híbridas oriundas destes cruzamentos foram plantadas em vasos na casa de vegetação, obtendo-se a população $F 1$, no total de 13 plantas, sendo 11 hibridas com IAC 17 e duas com Hartswille; a semente do híbrido com IAC 18 não germinou

As plantas F1 apresentaram um comportamento intermediário entre as duas espécies: vigorosas, de hábito de crescimento indeterminado, alto teor de gossipol e corolas com manchas de antocianina na base, caracte- 
rística da espécie selvagem, e folhas típicas e tamanho da corola de $G$. hirsutum. Todas estas plantas híbridas, porém, foram completamente estéreis, devendo haver uma instabilidade no pareamento cromossomico. Essa esterilidade também foi observada por KNIGHT (1954) em híbridos F1 de G. arboreum com $G$. hirsutum, a qual foi gradualmente restaurada mediante vários retrocruzamentos para os pais comerciais.

Contrariamente aos resultados observados por KNIGHT (1954), a restauração da fertilidade se deu, no presente trabalho, a partir do primeiro retrocruzamento, ou seja, a população $\mathrm{RC} 1$ apresentou-se totalmente fértil. Cabe ressaltar, porém, que a população $\mathrm{RCl}$ foi obtida com bastante dificuldade de "pegamento" nos cruzamentos. Foram realizados, em uma primeira etapa, 698 cruzamentos e obtidas 8 plantas e, numa segunda etapa, 471 cruzamentos, obtendo-se 9 plantas, apesar de ser utilizada, nestas duas etapas, a técnica de adição de um a três grãos de pólen próprio, no estigma do pai receptor, conforme BEASLEY (1940). Dos cruzamentos realizados anteriormente, sem o uso desta técnica, nenhum fruto foi obtido. Como se pode observar, a eficiência foi de apenas 1,45\% de "pegamento", em média, na obtenção desta população $\mathrm{RC} 1$ fértil A restauração da fertilidade pôde ser comprovada quando da realização do segundo retrocruzamento, o qual se deu mais facilmente, comparado com o primeiro $\mathrm{RC}$, pois foram realizados 153 cruzamentos com $86,27 \%$ de "pegamento" sem pólen próprio.

Além da completa restauração da fertilidade nas plantas RC1, foram recuperadas, também, algumas características agronômicas importantes de $G$. hirsutum, principalmente quanto a porte e ciclo anual, combinadas com as características da fibra de $G$. herbaceum var. africanum, superiores à das atuais variedades comerciais, como se pode observar nas figuras 1 e 2. Na primeira, compara-se a resistência da fibra em função do comprimento, e na segunda, a resistência em função da maturidade da fibra entre híbridos e variedades comerciais.

Como se pode notar, existe, neste híbrido, grande variabilidade genética para resistência da fibra, que deverá ser aproveitada na obtenção de novas variedades.

Dando prosseguimento ao programa de melhoramento, as sementes autofecundadas dessas 17 plantas foram semeadas em vasos em casa de vegetação e também em condições de campo, e, as plantas obtidas na geração (RC1)2, selecionadas individualmente, procurando aproveitar toda a segregação existente dentro desta população.

As observações de campo e os estudos dos caracteres agronomicos e tecnológicos da fibra, realizados nesta população, indicam a presença de plantas altamente promissoras. Os valores médios de 106 plantas selecionadas individualmente, e os menores e maiores valores encontrados na população, são comparados no quadro 2 , com a meta mínima a ser atingida para a obtenção de variedades comerciais. 


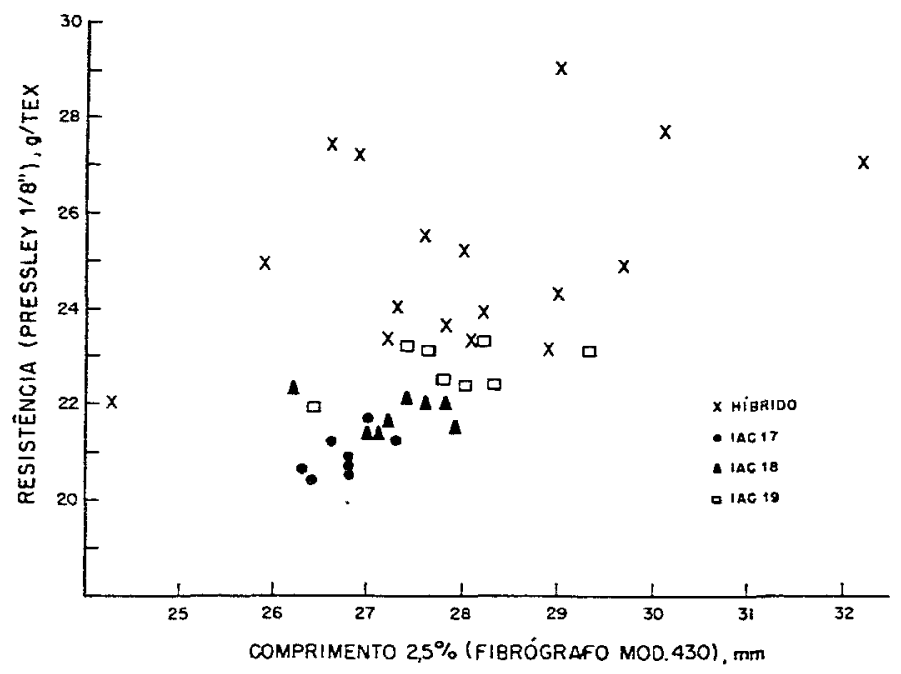

FIGURA 1 - Distribuição dos resultados obtidos com relação à resistência e comprimento da fibra, para as plantas do primeiro retrocruzamento entre as variedades comerciais de $G$. hirsutum IAC 17, IAC 18 e IAC 19 com a espécie $G$. herbaceum africanum duplicada.

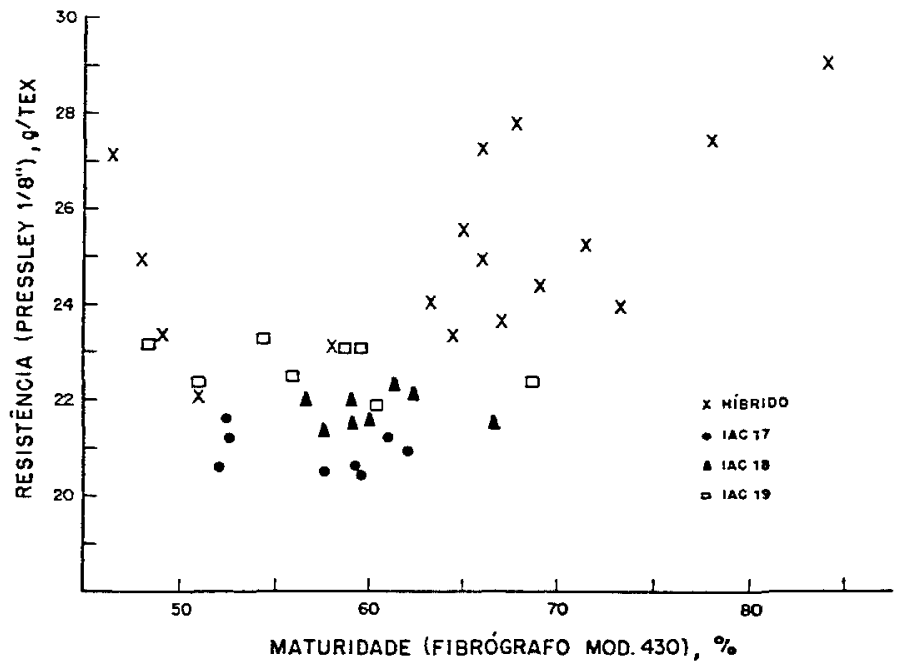

FIGURA 2 - Distribuição dos resultados obtidos com relação à resistência e à maturidade da fibra, para as plantas do primeiro retrocruzamento entre as variedades comerciais de $G$. hirsutum IAC 17, IAC 18 e IAC $19 \mathrm{com}$ a espécie $G$. herbaceum africanum duplicada. 
QUADRO 2 - Valores médios das caracteristicas agronomicas e tecnologicas da fibra de 106 plantas selecionadas individualmente, e menores e maiores valores encontrados nesta populaça hibrida (RC1) 2 de Gossypium hirsutum var. latifolium e $G$. herbaceum var. africanum duplicado, comparados com a meta mínima para obtençâo de variedades comerciais de algodoeiro e com valores médios do $G$. herbaceum africanum diplóide

\begin{tabular}{|c|c|c|c|c|c|}
\hline \multirow{2}{*}{$\begin{array}{l}\text { Características agronômicas } \\
\text { e tecnologicas da fibra }\end{array}$} & \multicolumn{3}{|c|}{ Hibrido } & \multirow{2}{*}{$\begin{array}{c}\begin{array}{c}\text { G. herbaceum } \\
\text { africanum diplóide }\end{array} \\
\begin{array}{c}\text { Valores } \\
\text { médios }\end{array}\end{array}$} & \multirow{2}{*}{$\begin{array}{c}\text { Variedades } \\
\text { comerciais } \\
\begin{array}{l}\text { Valures } \\
\text { medios }\end{array}\end{array}$} \\
\hline & $\begin{array}{l}\text { Menor } \\
\text { valor }\end{array}$ & $\begin{array}{l}\text { Média da } \\
\text { população }\end{array}$ & $\begin{array}{l}\text { Maior } \\
\text { valor }\end{array}$ & & \\
\hline Peso de 1 capulho (g) & 4,7 & 8,1 & 11,3 & 1,1 & 7,0 \\
\hline Fibra (名) & 35,40 & 39,21 & 43,10 & 18,5 & 40,00 \\
\hline Peso de 100 sementes (g) & 10,96 & 13,60 & 16,82 & 8.8 & 13,00 \\
\hline Resistência Pressley $1 / 8^{\prime \prime}(g /$ Tex) & 20,34 & 23,51 & 29,39 & 24.06 & 20,00 \\
\hline Comprimento $2,5 \% \mathrm{~mm}$ & 25,39 & 27,95 & 31,08 & 20.84 & 27,00 \\
\hline Uniformidade $50 / 2,5 \%$ & 42,08 & 46,22 & 57,94 & 51,89 & 45,00 \\
\hline Micronaire & 4,0 & 5,0 & 5,9 & 7,8 & 4.5 \\
\hline Maturidade \% & 59,69 & 61,12 & 70,63 & 86,83 & 60,00 \\
\hline
\end{tabular}

Como se pode observar, existe segregação para resistência da fibra na população hŕbrida, superior ao mínimo estabelecido para a obtenção de variedades comerciais de Gossypium hirsutum, e superior também ao índice de resistência do $G$. herbaceum var. africanum diplóide. As demais caracteristicas, também superiores aos pais, apresentam alta segregação, aparentemente transgressiva. Existe um equilíbrio aceitável entre as características, o qual foi rapidamente restabelecido, provavelmente pelo esquema de hibridação adotado, ou seja, a duplicação do número de cromossomos da espécie diplóide antes da realização dos cruzamentos.

Com base nesses resultados, não se pretende realizar novos retrocruzamentos, evitando, com isso, a formação de blocos de ligação de genes. O material deverá entrar na metodologia de melhoramento baseado na seleção genealógica dessas plantas, conforme esquema adotado pela Seção de Algodão do Instituto Agronômico, visando à obtenção de novas variedades.

\section{CONCLUSÕES}

Os resultados deste trabalho permitiram tirar as seguintes conclusões:

a) Os tratamentos de sementes com colchicina não se mostraram efi- 
cientes para a duplicação do número de cromossomos da espécie diplóide Gossypium herbaceum var. africanum, provavelmente pela sua condição selvagem.

b) O melhor tratamento para a obtenção de plantas tetraplóides desta espécie foi o de gemas apicais em pasta de lanolina mais colchicina $1 \%$, confirmando os resultados obtidos por STEPHENS (1940) em G. arboreum.

c) $\mathrm{O}$ "screening" inicial realizado nas plantas tratadas com colchicina, mediante observações das células dérmicas das páginas inferiores das folhas, dinamizou os trabalhos com grande número de plantas; o maior tamanho dessas células foi indício de plantas tetraplóides.

d) Observou-se esterilidade completa do F1 de cruzamento de variedades cultivadas de $G$. hirsutum com $G$. herbaceum v. africanum duplicada.

e) A fertilidade foi restaurada já no primeiro retrocruzamento, assim como foi recuperada a maioria das características economicas.

f) A espécie diplóide selvagem $G$. herbaceum var. africanum, escolhida para estes estudos, apresenta grande variabilidade genética para resistência da fibra e é possível a transferência deste caráter para a tetraplóide cultivada $G$. hirsutum var. latifolium, a partir da duplicação do número de cromossomos da diplóide, seguida da hibridação desta com a espécie cultivada.

\section{SUMMARY}

\section{INTERESPECIFIC HYBRIDIZATION BETWEEN GOSSYPIUM HIRSUTUM VAR.} LATIFOLIUM AND G. HERBACEUM VAR. AFRICANUM

Genetic variability was obtained by the authors for fiber strenght in cotton, through hybridization between the cultivated alotetraploid species Gossypium hirsutum L. var. latifolium Hutch. and the wild diploid species G. herbaceum L. africanum Hutch. The underlying methods and the hybrid's characteristics are reported and described. As a first step, the number of chromosomes in the diploid species was duplicated. Nine treatments with aqueous colchicine or colchicine in lanoline paste were carried out, comprising several concentrations and times of application to seeds, radicles and apical buds of the main stem. Success was obtained by treating apicalbuds with lanoline paste containing $1 \%$ colchicine, during 32 hours. Two hundred fourty five crosses between the duplicated africanum and cultivated varieties of cotton led to the obtention of thirteen sterile F1 plants. However, bud fertility was restaured after a first backcross. These back-crossed plants having promising agronomic characteristics and large variability for fiber strength, will be selected to develop a high fiber quality commercial variety.

Index terms: cotton breeding; $G$. hirsutum $\times$ G. herbaceum; chromosome duplication. 


\section{REFERÊNCIAS BIBLIOGRÁFICAS}

AMIN, K.C. Interespecific hybridization and colchicine induced polyplody and use of colchicine in cotton. Ind. Cent. Cot. Comt. Gnt. and Pl. Br., 1941. 14p. (Paper, 5)

BEASLEY, J.O. Hibridization of American 26-Chromosome and asiatic 13Chromosome species of Gossypium. Journal of Agricultural Research, 60(3): 175-182, 1940.

Meiotic chromosome behavior in species, species hybrids, haploids, and induced poly ploids of Gossypium. Genetics, 27:25-54, 1942.

The production of polyploids in Gossypium. Journal of Heredity, 31:39-48, 1940.

GRIDI-PAPP, I.L. Botânica e genética. In: INSTITUTO BRASILEIRO DE POTASSA. Cultura e adubação do algodoeiro. Sao Paulo, 1965. p.117160.

Índice morfologico baseado na variação relativa das dimensões em Gossypium tetraplóide. Piracicaba, Escola Superior de Agricultura "Luiz de Qu eiroz", 1970. 44f. Tese (Doutoramento)

KNIGHT, R.L. Breeding Sudan cottons. Empire Cotton Growing Review, 11(1):1-11, 1954.

LODEN, H.D. Speciation within Gossypium and hibridization of Gossypium hirsutum with other members of the genes. In: ANNUAL COTTON IMPROVEMENT CONFERENCE AND ASSOCIATION OF SOUTHERN AGRICULTURAL WORKERS, 3., Memphis, Tennessee, 1951. 16p. (Separata)

MENDES, A.J.T. Algodðes poliplóides obtidos pela colchicina; observações citológicas em Gossypium hirsutum octoplóide. Bragantia, Campinas, 2:101-1 10, 1942.

. Duplicação do número de cromossomos em cafe, algodđo e fumo, pela ação da colchicina São Paulo, Secretaria da Agricultura, Indústria e Comércio do Est. São Paulo, 1939. 28 p. (Boletim Técnico, 57)

MEYER, R.J. Plant and fiber properties of Gossypium species for possible transfer to Upland. Leland, Mississippi, Delta Branch Exp. Station, 1953. (Mimeografado)

MIRZA, M.A. Effects of various doses of colchicine on cotton. Journal of Agricultural Research, West Pakistan, 12(1):23-30, 1974.

STEPHENS, S.G. Citogenetic methods of measuring interespecific relationship in Gossypium. Raleigh, University of North Carolina, 1954. (Mimeografado) 
STEPHENS, S.G. Colchicine-produced polyploids in Gossypium. I. An autotetraploid Asiatic cotton and certain of its hybrids with wild diploid species. Journal of Genetic, 44: 272-295, 1942.

. Colchicine treatment as a means of inducing polyploidy in cotton. Tropical Agriculture, Trinidad, 17:23-25, 1940. 